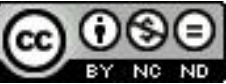

\section{Modelagem na Sala de Aula: resistências e obstáculos}

\section{Mathematical Modeling in the Classroom: resistance and obstacles}

\author{
Everaldo Silveira* \\ Ademir Donizeti Caldeira**
}

\begin{abstract}
Resumo
Este artigo tem como objetivo descrever e analisar os obstáculos e resistências de professores e futuros professores, egressos de cursos de formação, em desenvolver atividades relacionadas à Modelagem na Educação Matemática nas suas práticas docentes, conforme relatado em dissertações e teses. Para a obtenção dos dados, fez-se um recorte do trabalho de Silveira (2007), no qual se analisam 14 das 65 teses e dissertações sobre Modelagem produzidas entre 1976 e 2005. Os resultados nos mostraram que os professores cursistas apresentam algumas resistências à prática de sala de aula com a Modelagem, sendo que essas resistências se mostram nas relações do professor com o trabalho, com a escola, com o currículo, com os alunos e com a família dos alunos.
\end{abstract}

Palavras-chave: Educação Matemática. Modelagem Matemática. Formação de Professores. Obstáculos e Resistências.

\begin{abstract}
This article describes and analyzes obstacles and resistance reported by teachers and future teachers who are university graduates in developing modeling-related tasks in

"Doutorando em Educação Científica e Tecnológica pela Universidade Federal de Santa Catarina (UFSC), Florianópolis, SC, Brasil. Professor Colaborador da Faculdade de Educação (FAED) da Universidade Estadual de Santa Catarina (UDESC), Santa Catarina, SC, Brasil. Endereço para correspondência: Rua Capitão Romualdo de Barros, 861, A.p. 303, Bl 5, Bairro Saco dos Limões, CEP: 88040-600, Florianópolis, SC, Brasil.E-mail: derelst@hotmail.com

**Doutor em Educação pela Universidade Estadual de Campinas (UNICAMP). Professor Adjunto III do Departamento de Metodologia do Ensino do Centro de Educação e Ciências Humanas da Universidade Federal de São Carlos (UFSCar). Endereço para correspondência: Rua Roberval Pozzi, 50, Santa Marta, CEP 13564-230, São Carlos, SP, Brasil. E-mail: miro@ufscar.br
\end{abstract}


their teaching practices. These teachers were the subject of research reported in theses and dissertations about modeling produced in Brazil. Fourteen out of 65 theses and dissertations about modeling analyzed by Silveira (2007), produced between 1976 and 2005 , were analyzed. The results showed that the teachers of the courses presented some resistance to using modeling in the classroom practice, and that this resistance was evident in the relations of the teacher with the work, the school, the curriculum, the students, and the students' families.

Keywords: Mathematical Education. Mathematical Modelling. Teacher Training. Obstacles and resistance.

\section{Introdução}

Este artigo apresenta os resultados de uma pesquisa que teve por objetivo descrever e analisar obstáculos e resistências de professores, futuros professores e egressos de cursos de formação, em desenvolver atividades relacionadas à Modelagem $^{1}$ na Educação Matemática e em suas práticas docentes. Tais professores, doravante chamados de professores cursistas, foram sujeitos de pesquisas relatadas em teses e dissertações sobre Modelagem, produzidas no Brasil no período de 1976 a 2005. Portanto, neste estudo, debruçamo-nos sobre dados secundários, ou seja, coletados em outros estudos. Procedemos à análise transversal para dar conta do propósito aqui alinhavado.

Neste artigo, a ênfase é dada em apresentar os obstáculos e resistências de tais professores em aplicar a Modelagem na prática em sala de aula, por acreditarmos ser uma das vertentes mais importantes quando argumentamos que a Modelagem é uma concepção de educação matemática e não apenas uma metodologia (CALDEIRA, 2009). Além disso, os trabalhos que serão apresentados a seguir, mostram fragilidades nesse campo.

Sustentamos a perspectiva da Modelagem enquanto uma concepção de Educação Matemática por acreditarmos que ela está intimamente relacionada à concepção de Matemática alinhada à de Gottschalk (2004; 2008), sustentada pela filosofia da linguagem de Wittgenstein (1999). Esta elabora o que chamamos de Matemática como regras e convenções estabelecidas dentro de um determinado contexto social, histórico e cultural, permeado por relações de poder, diferentemente daquela, por exemplo, vista como uma descoberta.

Assim, entendemos Matemática nessa vertente sociocultural, cujo foco

\footnotetext{
${ }^{1}$ Neste texto utilizamos Modelagem como sinônimo da expressão Modelagem na Educação Matemática.
} 
está na visão de que não existe apenas uma Matemática, mas várias, e que essa, que aprendemos e ensinamos na escola, trata-se de um conjunto dessas regras e convenções, tão importantes quanto outras, que existem ou poderão ser produzidas em outros contextos culturais.

Numa perspectiva mais ampliada do que a de ser apenas um método para se ensinar a Matemática, a partir de um determinado programa hegemônico, pré-determinado como conhecimento universal, a Modelagem abre a possibilidade de se resgatar outras formas de trabalhar com a Matemática, bem como o surgimento de outros conteúdos, aproximando-se daquilo que D’Ambrosio (2001) denomina de Programa Etnomatemática.

A aproximação se justifica pelo fato de a Modelagem, no nosso entendimento, sempre trabalhar com problemas da realidade do aluno. Como podemos ter alunos das mais variadas formas de vida (intracultural), podemos encontrar, também, além da Matemática dita universal, que deve ser ensinada pelo professor, outras formas de pensar e agir as quais devem ser aprendidas, discutidas e tomadas como comparação com aquela, dita universal.

Além disso, dentro do próprio programa institucional e hegemônico, alguns conteúdos podem ser deixados de lado em detrimento da necessidade de aprender outros, para a compreensão de algum fenômeno advindo dos temas os quais devem ser trabalhados no processo de Modelagem.

Assim, a Modelagem, na perspectiva defendida por Caldeira (2009), vai problematizar o programa e usar as ferramentas matemáticas para um tipo de problema específico, que está sendo investigado em um determinado momento, aproximando-se da concepção de currículo defendida por D'Ambrosio (1999) a partir dos conceitos de literacia, materacia e tecnocracia.

Em se tratando da Modelagem, haverá, sempre, um planejamento de curso e um produto final, pois quando o professor estimula os alunos a participarem do processo, o programa vai sendo construído ao longo da trajetória do ano letivo.

Não se trata de um programa pronto e acabado, mas que pode ser construído pelos alunos com o auxílio do professor, de fora para dentro da escola, e não como, tradicionalmente, estamos acostumados a ver, somente da escola para os alunos.

Desse modo, o papel do professor é fazer com que os alunos possam comparar os conteúdos advindos da Matemática dita universal com os possíveis conteúdos advindos da cultura local. 


\section{Aspectos metodológicos}

Apesar da existência de outros trabalhos focados nos mapeamentos sobre Modelagem - Biembengut, Hein e Dorow (2007); Barbosa, (2007); Biembengut (2009); Biembengut, Schmitt e Vieira (2009); Fiorentini (1996) optamos pelo recorte de Silveira (2007), que selecionou dezesseis trabalhos sobre formação de professores, dentro de um universo de sessenta e cinco teses e dissertações sobre Modelagem, defendidas no Brasil no período de 1976 a 2005.

Para realizar essa seleção, Silveira (2007) criou e utilizou alguns critérios, que enumeramos a seguir.

1. Busca no banco de teses e dissertações da Capes segundo alguns descritores (como modelagem matemática educação, modelagem matemática ensino, modelação matemática educação etc.), em que quarenta e três trabalhos foram localizados.

2. Busca nos currículos lattes dos professores que orientaram os quarenta e três trabalhos listados no primeiro critério, resultando em quatro novos trabalhos.

3. Busca nos currículos lattes de todos os participantes da IV Conferência Nacional de Modelagem na Educação Matemática, que aconteceu em 2005, na Universidade Estadual de Feira de Santana, evento que congregou os principais pesquisadores desse campo. Tais buscas nos forneceram mais onze trabalhos.

4. Trabalhos sugeridos por Fiorentini (1996) no artigo Estudo de algumas tentativas pioneiras de pesquisa sobre o uso da Modelagem Matemática no ensino, que contribuiu com três dissertações.

5. Busca no acervo do Centro de Referência de Modelagem Matemática no Ensino da Fundação Universitária de Blumenau, resultando em quatro trabalhos.

Para nosso corpus, optamos por quatorze dos dezesseis trabalhos, inicialmente, recortados por Silveira (2007), os quais estão elencados no Quadro 1, por considerarmos que dois deles não serviriam aos propósitos deste artigo.

Para a obtenção dos nossos dados, buscamos, nos quatorze trabalhos, aspectos que revelavam algum tipo de resistência ou obstáculo por parte dos professores cursistas no desenvolvimento das atividades de Modelagem em suas práticas pedagógicas. 


\begin{tabular}{|c|c|c|}
\hline AUTOR (ANO) & TITULO & STATUS \\
\hline Dias (2005) & $\begin{array}{l}\text { Uma experiência com Modelagem Matemática na formação } \\
\text { continuada de professores }\end{array}$ & Dissertação \\
\hline Fidelis (2005) & 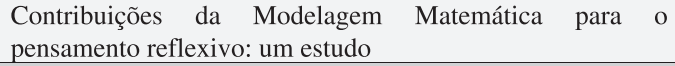 & Dissertação \\
\hline Jacobini (2004) & $\begin{array}{l}\text { A Modelagem Matemática como instrumento de ação } \\
\text { política na sala de aula }\end{array}$ & Tese \\
\hline Luz (2003) & $\begin{array}{l}\text { Educação a Distância e Educação Matemática: } \\
\text { contribuições mútuas no contexto teórico-metodológico }\end{array}$ & Tese \\
\hline Stahl (2003) & $\begin{array}{l}\text { O ambiente e a Modelagem Matemática no ensino de } \\
\text { cálculo numérico }\end{array}$ & Tese \\
\hline Roma (2002) & $\begin{array}{l}\text { O curso de especialização em Educação Matemática da } \\
\text { PUC-Campinas: reflexos na prática pedagógica dos } \\
\text { egressos }\end{array}$ & Dissertação \\
\hline Barbosa (2001) & $\begin{array}{l}\text { Modelagem Matemática: concepções e experiências de } \\
\text { futuros professores }\end{array}$ & Tese \\
\hline Caldeira (1998) & $\begin{array}{l}\text { Educação Matemática e Ambiental: um contexto de } \\
\text { mudança }\end{array}$ & Tese \\
\hline Gavanski (1995) & $\begin{array}{l}\text { Uma experiência de estágio supervisionado norteado pela } \\
\text { Modelagem Matemática: indícios para uma ação inovadora }\end{array}$ & Dissertação \\
\hline Martinello (1994) & $\begin{array}{l}\text { Modelação Matemática, uma alternativa para o ensino da } \\
\text { Matemática no primeiro grau }\end{array}$ & Dissertação \\
\hline Burak (1992) & $\begin{array}{l}\text { Modelagem Matemática: ações e interações no processo de } \\
\text { ensino aprendizagem }\end{array}$ & Tese \\
\hline Anastácio (1990) & $\begin{array}{l}\text { Considerações sobre a Modelagem Matemática e a } \\
\text { Educação Matemática }\end{array}$ & Dissertação \\
\hline Gazzetta (1989) & $\begin{array}{l}\text { A Modelagem como estratégia de aprendizagem da } \\
\text { Matemática em cursos de aperfeiçoamento de professores }\end{array}$ & Dissertação \\
\hline Burak (1987) & $\begin{array}{l}\text { Modelagem Matemática: uma metodologia alternativa para } \\
\text { o ensino de Matemática na } 5^{\mathrm{a}} \text { série }\end{array}$ & Dissertação \\
\hline
\end{tabular}

Quadro 1 - Teses e Dissertações que versam sobre Modelagem Matemática e Formação de Professores.

Fonte: (SILVEIRA, 2007, p. 80-81)

Embora optemos por analisar os trabalhos voltados à formação inicial ou continuada, não pretendemos, aqui, dicotomizá-los, tornando-os estanques. Optamos por considerar que a formação de professores deve ser entendida sob a perspectiva de começar com a formação inicial e estender-se, ao longo da carreira profissional, por meio de um processo contínuo.

Dessa forma, a divisão dos quatorze trabalhos, no que tange ao tipo de formação discutida em cada pesquisa, ficou assim distribuída:

- Formação inicial: seis trabalhos, sendo quatro teses e duas dissertações, os quais foram desenvolvidos com alunos da licenciatura em Matemática.

- Formação continuada: sete trabalhos, sendo duas teses e cinco dissertações. Os cursos foram desenvolvidos basicamente com 
professores de ensino fundamental e médio.

- Outro: Um trabalho desenvolvido a partir de dados coletados por meio de questionário aos egressos de um Curso de Especialização em Etno/ Modelagem.

\section{Descrições dos trabalhos}

\subsection{Formação inicial}

Ao falar em formação inicial, estamos nos referindo àquela que acontece ainda no período em que o futuro professor está cursando a graduação. Consideramos, aqui, além da própria licenciatura, os cursos extracurriculares.

Do total do corpus analisado, seis dissertações ou teses (BARBOSA, 2001; FIDELIS, 2005; GAVANSKI, 1995; JACOBINI, 2004; LUZ, 2003; STAHL, 2003) relatam cursos de Modelagem desenvolvidos com licenciandos em Matemática. Quatro deles (FIDELIS, 2005; GAVANSKI, 1995; JACOBINI, 2004; STAHL, 2003) foram desenvolvidos em relação a alguma disciplina do curso. Desses, três relatam atividades relacionadas à Matemática do Ensino Superior, e um (GAVANSKI, 1995) relata atividades de estágio supervisionado, no qual os licenciandos desenvolveram um minicurso com duração de 40h, em horário extraclasse, destinado aos alunos da $7^{a}$ série de escola pública.

Dos dois trabalhos restantes, um deles (BARBOSA, 2001) relata o desenvolvimento de um curso extracurricular, de extensão, para licenciandos em Matemática, o qual serviu também de formação continuada para uma professora em exercício; e o outro (LUZ, 2003) relata a aplicação de um curso de Modelagem à distância para licenciandos em Matemática de universidades catarinenses.

\subsection{Desenvolvimento de cursos de formação inicial no âmbito de uma disciplina específica}

Fidelis (2005) pesquisa o curso oferecido por sua orientadora aos licenciandos em Matemática. Durante o curso, eles foram convidados a discutir textos de pesquisadores da área, e, em seguida, resolverem atividades de Modelagem propostas pela professora. Basicamente, a Matemática discutida é a do Ensino Superior. Os licenciandos tiveram a oportunidade de escolher temas provenientes de sua realidade para tais atividades de Modelagem. 
Esse autor coletou dados referentes a três licenciandos do curso, seus sujeitos de pesquisa, os quais mostraram alguma disposição em desenvolver atividades de Modelagem em suas futuras classes. Um deles revelou que já era professor e que havia utilizado tal estratégia de ensino, apontando interesse em continuar esse trabalho.

Porém, os outros dois apresentaram algumas ressalvas: um demonstrou, segundo o autor, preocupação com tais trabalhos, por acreditar que levam um tempo maior do que as aulas normais, mostrando sinais de preocupação com o cumprimento do conteúdo preestabelecido (FIDELIS, 2005); o outro, que ainda não tinha decidido sobre o uso da Modelagem nas suas futuras aulas, se preocupou com as dificuldades dos alunos em relação aos detalhes envolvidos no processo de Modelagem (FIDELIS, 2005).

Já Gavanski (1995) relata a experiência desenvolvida com licenciandos do curso de Prática de Ensino na Licenciatura em Matemática. A pesquisadora ofereceu um curso para os alunos, no qual foram discutidos apenas aspectos teóricos da Modelagem, não fazendo menção a atividades práticas. Na continuação do semestre, os licenciandos foram convidados a desenvolver um minicurso de Modelagem com alunos da então $7^{\mathrm{a}}$ série do Ensino Fundamental de uma escola pública. No minicurso foram propostos quatro temas aos alunos, para que escolhessem um por intermédio de votação.

Os licenciandos foram se revezando em duplas, de modo a orientar as atividades dos alunos. A pesquisadora relata que, da metade do curso em diante, os licenciandos, embora participassem dos encontros, não demonstravam a mesma motivação ou disposição inicial.

Jacobini (2004) desenvolveu um projeto com licenciandos em Matemática a partir de uma disciplina específica, com um projeto desenvolvido como atividade extracurricular, contando com a participação de apenas quatro alunos. Nesse projeto, denominado Pesquisa de intenção de votos dos estudantes da PUCCampinas, os alunos estudaram conteúdos relacionados à Estatística. $\mathrm{O}$ pesquisador analisou as possibilidades de crescimento político dos estudantes quando a Modelagem é adotada como estratégia de ensino-aprendizagem.

Embora esse autor afirme que alguns participantes, após a conclusão dos trabalhos, continuaram envolvidos com atividades no Laboratório de Ensino de Matemática, e que os licenciandos estiveram sempre envolvidos com os trabalhos, não há relato sobre possíveis manifestações dos cursistas no que se refere à possibilidade do desenvolvimento de atividades de Modelagem ao se tornarem professores. 
Stahl (2003) relata a experiência do desenvolvimento de um curso de Cálculo Numérico com atividades de Modelagem em uma turma de Licenciatura em Matemática. Segundo ele, "a cada novo conteúdo a classe é provocada pelo professor de modo a gerar um tema/problema de origem ambiental" (STAHL, 2003, p. 58). Não identificamos neste trabalho qualquer evidência sobre a possível continuidade ou não da Modelagem pelos licenciandos cursistas em suas futuras atividades de docência.

\subsection{Desenvolvimento de curso de extensão no âmbito da formação inicial}

Barbosa (2001) relata o desenvolvimento de um curso de extensão denominado de Modelagem e Educação Matemática, com licenciandos em Matemática, o qual serviu, também, de formação continuada para uma professora em exercício. O curso assentou-se em dois pilares: i) "Indagar/investigar situações com referência na realidade através da Modelagem; ii) Reflexão deste ambiente do ponto de vista da prática de sala de aula" (BARBOSA, 2001, p.102).

Desse modo, o autor programou seis tipos de atividades para esse curso. São elas: "Estudo de situações-problema; Natureza e método de Modelagem; Modelagem "empírica"; Casos de Modelagem; Casos de sala de aula; Projeto de Modelagem e Ensino" (BARBOSA, 2001, p.106).

A partir desse curso, o autor afirma que as licenciadas, sujeitos da sua pesquisa, demonstraram simpatia à utilização da Modelagem, deixando transparecer sua aceitação quanto à presença desse ambiente de aprendizagem nas aulas de Matemática. "Entretanto, as futuras professoras manifestaram reticência, cautela e/ou insegurança em relação à Modelagem em suas futuras práticas de ensino" (BARBOSA, 2001, p.216).

\section{Desenvolvimento de curso de formação à distância no âmbito da formação inicial}

Luz (2003) relata uma experiência de um curso de formação a distância, com licenciandos em Matemática de diversas cidades de Santa Catarina. O curso oferecido foi mediado por um ambiente virtual, por meio do qual foram desenvolvidas algumas atividades práticas de Modelagem.

Inicialmente, a autora planejou um curso para sessenta licenciandos. Devido à grande procura, ela aumentou o número de vagas para setenta e cinco. Desses, nove nunca se posicionaram, e apenas vinte e um concluíram o curso. 
O número de acessos ao ambiente virtual caiu de cento e sessenta, na primeira semana, para menos de vinte, na última. Ela atribuiu esse elevado número de desistências à dificuldade de acesso a computadores e internet.

A autora também descreve alguns empecilhos dos licenciandos em relação ao curso. Ela observou "uma grande insegurança por parte dos alunos e um temor por estarem publicando algo 'errado' que ficaria exposto ao professor e a todos os colegas de curso" (LUZ, 2003, p.98). O termo publicando faz referência às publicações dos alunos no ambiente virtual.

\section{A formação continuada}

A formação continuada é assumida, neste trabalho, como aquela que acontece para além da certificação oficial e em época diferente desta, de tal forma que possibilite um desenvolvimento profissional. Consideramos que sete trabalhos (CALDEIRA, 1998; ANASTÁCIO, 1990; BURAK, 1987; BURAK, 1992; DIAS, 2005; GAZZETTA, 1989; MARTINELLO, 1994) relatam o desenvolvimento de atividades visando à formação de professores em atividade.

Três deles (BURAK, 1987; ANASTÁCIO, 1990; MARTINELLO, 1994) relatam o desenvolvimento de atividades com professores atuantes no ensino fundamental; outros três (CALDEIRA, 1998; BURAK, 1992; DIAS, 2005) relatam experiências de formação de professores do ensino fundamental e médio, e, um deles (GAZZETTA, 1989), além de relatar o trabalho com professores do ensino fundamental e médio, se refere, também, a cursos de especialização que contaram com a presença de professores que atuavam no ensino superior.

\subsection{Cursos de formação continuada de professores do ensino fundamental}

Burak (1987) desenvolveu cursos com professores de $5^{\mathrm{a}}$ série, trabalhando, principalmente, com construção de maquetes de casa. $\mathrm{O}$ autor relata que abriu sessenta vagas para um curso de Modelagem, porém o número de concluintes foi de quarenta. Nesse caso, ele atribui o número de desistências às condições climáticas do momento.

Ao se referir à postura dos professores, o autor afirma que "[...] quase nenhuma atividade conseguiu ser elaborada pelos professores no decorrer do curso. O que observamos foi a passividade diante de uma situação problema" (BURAK, 1987, p.67). Para o autor, uma das causas de tal acontecimento foi a proposta de que os professores trabalhassem individualmente. 
Anastácio (1990) desenvolveu um curso com professores de $5^{\mathrm{a}}$ serie. Primeiramente, realizou uma discussão teórica com os professores cursistas, na qual argumentaram sobre a necessidade de procurar alternativas para o ensino de Matemática.

Depois disso, discutiram quatro modelos apresentados em um texto, partindo das seguintes questões: O que você poderia aprender sobre Modelagem Matemática no texto estudado? Quais características apresentam o trabalho com Modelagem Matemática? A partir dessas questões, os grupos escolheram temas, coletaram dados e desenvolveram modelos.

Dos vinte e um professores inscritos, apenas dezesseis estiveram presentes e somente onze concluíram. Destes, oito demonstraram interesse em aplicar as atividades nas suas classes, porém apenas quatro o fizeram. Já no ano seguinte, apenas um dos professores continuou aplicando Modelagem em sua prática pedagógica em sala de aula.

Martinello (1994) relata alguns cursos oferecidos em conjunto com sua orientadora para professores de $5^{\mathrm{a}}$ a $8^{\mathrm{a}}$ séries. Os professores começaram o curso com uma visita a uma fábrica de palitos de picolé, onde coletaram dados e tentaram formular situações-problema. Posteriormente, o autor sugeriu modelos matemáticos para as situações pesquisadas. Nessa etapa, foram elaboradas situações-problema reais para as quais foram buscadas soluções matemáticas. A pesquisadora ainda relata uma terceira etapa e um curso de aperfeiçoamento.

Segundo o autor, quarenta e cinco professores participaram da primeira etapa. Ela afirma que "a terceira etapa do curso de aperfeiçoamento foi realizada com o mesmo entusiasmo, com o mesmo afinco e dedicação” (MARTINELLO, 1994, p. 96) e afirma que apenas "quatro se propuseram a trabalhar a modelação matemática” (MARTINELLO, 1994, p. 97).

\subsection{Cursos de formação continuada de professores do ensino fundamental e médio}

Caldeira (1998) desenvolveu um curso com professores da rede pública municipal de ensino. Ele iniciou o curso com uma discussão sobre as relações entre Educação Ambiental e Modelagem Matemática por meio de palestras, vídeos, filmes, apresentação de seminários, discussões e atividades de campo. $\mathrm{Na}$ sequência, os professores se agruparam e escolheram os temas que gostariam de trabalhar. Em seguida, os grupos atuaram etnograficamente, levantando dados sobre os seus temas. Finalmente, desenvolveram modelos para solucionar os 
problemas.

Dos dezoito professores que terminaram a primeira etapa do seu curso, apenas cinco se propuseram a trabalhar com seus alunos. Os demais apresentaram motivos variados; porém o autor afirma que, para os que desejaram continuar com o projeto, a motivação foi a perspectiva de mudarem e aperfeiçoarem sua prática pedagógica. No entanto, essa vontade não foi muito duradoura, pois, das cinco professoras que começaram a desenvolver atividades de Modelagem com seus alunos, apenas duas desenvolveram-na até o final do processo. As restantes, após uma tentativa inicial, acabaram desistindo. Uma das desistentes afirmou que iria inserir em sua prática pedagógica o trabalho com os jogos e a outra preferiu voltar à forma tradicional de ensino.

Burak (1992) relata sua experiência em curso desenvolvido com professores do então $1^{\circ}$ e $2^{\circ}$ graus da rede estadual de educação. Os professores, em grupos, escolheram temas para o trabalho.

$\mathrm{O}$ autor afirma ter realizado, antes da pesquisa de campo, um estudo sobre as abordagens qualitativas de pesquisa em educação, objetivando, de forma superficial, as etapas do método etnográfico de pesquisa, o que, segundo ele, conciliava harmoniosamente com o desenvolvimento de atividades com o método da Modelagem Matemática.

Embora, segundo relato do autor, os professores tenham encontrado grandes dificuldades para o desenvolvimento das atividades de Modelagem, comentaram que gostariam de dar continuidade aos trabalhos.

Dias (2005) desenvolveu um curso em colaboração com a sua orientadora. A autora enumera três condições que devem ser atendidas por um programa de formação que pretende envolver o professor com a Modelagem Matemática. A saber: "aprender sobre a Modelagem Matemática; aprender por meio da Modelagem Matemática; ensinar usando Modelagem Matemática" (DIAS, 2005, p. 46).

Ela afirma que tinha interesse em teorizar a Modelagem, objetivando uma "compreensão acerca dessa alternativa de ensino, além de proporcionar a eles uma reflexão sobre a atividade de Modelagem do ponto de vista prático da sala de aula" (DIAS, 2005, p. 54). Assim, foi desenvolvido um conjunto de atividades de Modelagem. A autora abriu espaço para que os professores relatassem experiências acerca de atividades de Modelagem desenvolvidas em suas classes.

Em seu relato, ao analisar os dados coletados de sete professores participantes do curso, nos informa que, ao perguntar se é interessante trabalhar 
com Modelagem, todos os professores diziam que sim. Porém, em alguns fragmentos de falas dos professores, constatamos alguns obstáculos quanto à aplicabilidade da Modelagem em sala de aula. Transcrevemos alguns destes fragmentos, citados pela autora:

“[...] dá insegurança de não saber que modelo vai se chegar ou que Matemática usar" (DIAS, 2005, p. 74).

“[...] não sei se utilizando Modelagem Matemática seria capaz de dar conta de todo o conteúdo" (DIAS, 2005, p. 74).

“[...] exige mais do professor na preparação e no momento da aula" (DIAS, 2005, p. 75).

"Não dá para planejar quanto tempo será necessário para desenvolver uma atividade" (DIAS, 2005, p. 75).

\subsection{Cursos de formação continuada de professores do ensino fundamental, médio e superior}

Gazzetta (1989) relata sobre cursos de especialização voltados à Modelagem, dos quais participou como docente. As disciplinas sempre estiveram ligadas às atividades práticas de Modelagem, não havendo relato de discussões de textos de fundamentação sobre o assunto.

A autora, ao referir-se à continuidade do trabalho pelos professores concluintes dos seus cursos, diz não ter informações sistemáticas; afirma, porém, que alguns professores ainda mantinham contato com ela no período que estava no mestrado, e que alguns relatavam o desenvolvimento de atividades nos vários níveis de ensino. A autora apresenta uma tabela na qual relaciona três cursos dados, em três cidades diferentes, que geraram trabalhos de Modelagem desenvolvidos por sete professores.

\section{Outro tipo de relato sobre formação de professores}

O autor desse trabalho, Roma (2002), não desenvolveu e nem acompanhou o desenvolvimento de curso sobre formação de professores em Modelagem. Para conseguir seus dados, valeu-se, apenas, de questionários que foram enviados aos egressos do Curso de Especialização em Educação 
Matemática da PUC-Campinas, intitulado A Etno/Modelagem Matemática Aplicada ao Ensino Fundamental e Médio, com os quais buscou por indicadores que demonstrassem a utilização ou não da estratégia metodológica da Modelagem. Esse autor ainda procurou analisar as implicações de tal prática pedagógica, nos casos em que os professores relataram que estavam ou estiveram utilizando, em termos de: motivação dos alunos, envolvimento com o projeto, dificuldades encontradas, manifestação/reação da escola e dos pais.

$\mathrm{O}$ autor buscou contato com cento e quarenta e um egressos desse curso e obteve apenas sessenta e cinco respostas. Foi enviado um questionário a cada um dos sessenta e cinco egressos, dos quais apenas trinta e um retornaram. Dos trinta e um professores que responderam o questionário, apenas quinze afirmaram que já haviam utilizado, de alguma forma, a estratégia da Modelagem. Esses professores relataram o desenvolvimento de vinte projetos, porém, de acordo com a classificação criada pelo autor, três projetos eram especificamente voltados à Modelagem e ao Ensino de Estatística, dois envolveram PréModelação ${ }^{2}$, quatro se encaixaram perfeitamente com a estratégia da Modelagem, e onze referiam-se ao que ele chamou de "simplesmente Projetos Escolares" (ROMA, 2002, p. 70).

\section{Principais obstáculos para o desenvolvimento da Modelagem em sala de aula}

As descrições sobre os trabalhos tidos como foco deste artigo evidenciaram algumas preocupações com a efetiva concretização, por parte dos cursistas, em desenvolver atividades de Modelagem nas suas práticas de sala de aula. Apesar de, enquanto cursistas, demonstrarem interesse na aplicação da Modelagem, demonstraram, também, certa restrição na sua aplicação.

Tais descrições evidenciaram algumas resistências e obstáculos, que caracterizamos em cinco grupos não estanques entre si. Optamos em caracterizálos mais no sentido de oferecer à comunidade de pesquisadores e professores interessados neste assunto um panorama mais didático, do que propriamente enquadrar tais características em um determinado contexto.

As aplicações em Modelagem são complexas demais para, assim, simplesmente, caracteriza-las entre grupos de professores, alunos, pais e escola. Existe uma unicidade e uma interdependência entre esses quatro aspectos,

\footnotetext{
${ }^{2}$ Segundo Biembengut (1999, p. 48), um trabalho de pré-modelação é aquele em que cada um dos conteúdos do programa é apresentado a partir de modelos já conhecidos.
} 
portanto, não podemos querer analisá-los separadamente.

Os grupos, apresentados no Quadro 2, foram nomeados da seguinte forma: o professor e suas relações com o trabalho; o professor e suas relações com a escola; o professor e suas relações com o currículo; os alunos e suas relações com a escola e os professores e suas relações com a família dos alunos.

\begin{tabular}{|c|c|}
\hline CATEGORIAS & ÁCULOS E RESITÊNCIAS \\
\hline $\begin{array}{l}\text { Professor } e \text { suas } \\
\text { relações com o } \\
\text { trabalho }\end{array}$ & $\begin{array}{l}\text { - Maior exigência do professor na preparação e no momento da aula (ROMA, } \\
\text { 2002; JACOBINI, 2004; DIAS, 2005). } \\
\text { Insegurança diante do novo (BURAK, 1987, 1992; GAZZETTA, 1989; } \\
\text { ANASTÁCIO, 1990; GAVANSKI, 1995; CALDEIRA, 1998; BARBOSA, } \\
\text { 2001; DIAS, 2005) } \\
\text { O não acompanhamento de um profissional que tenha maior experiência e } \\
\text { domínio sobre a Modelagem Matemática (BURAK, 1992). } \\
\text { Grande quantidade de alunos por turma (ANASTÁCIO, 1990; BARBOSA, } \\
\text { 2001). }\end{array}$ \\
\hline 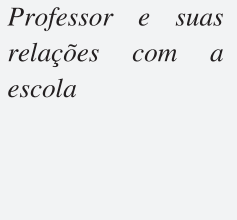 & $\begin{array}{l}\text { - Ausência de colaboração da parte administrativa da escola (ANASTÁCIO, } \\
\text { 1990; BURAK, 1992; MARTINELLO, 1994; BARBOSA, 2001; ROMA, } \\
\text { 2002) } \\
\text { Estrutura da escola (BARBOSA, 2001). } \\
\text { Objetivos diferentes dos objetivos da instituição (ROMA, 2002; FIDELIS, } \\
\text { 2005). }\end{array}$ \\
\hline $\begin{array}{l}\text { Professor e suas } \\
\text { relações com o } \\
\text { currículo }\end{array}$ & 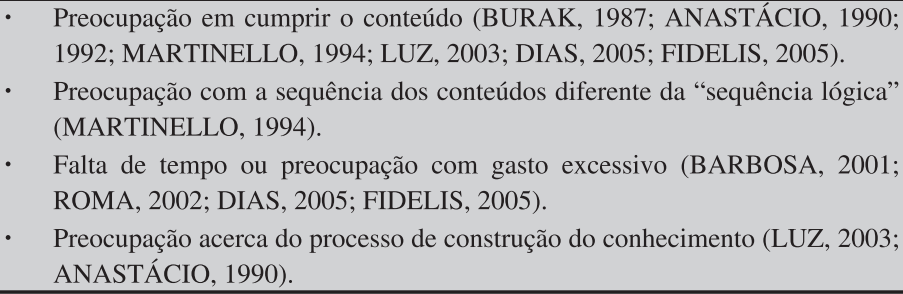 \\
\hline $\begin{array}{l}\text { Alunos e suas } \\
\text { relações com } \quad \text { a } \\
\text { Modelagem }\end{array}$ & $\begin{array}{l}\text { - } \quad \text { Reação dos alunos (BARBOSA, 2001). } \\
\text { Indisposição e cansaço por parte dos alunos do noturno em desenvolver as } \\
\text { atividades (ROMA, 2002). } \\
\text { - Os alunos não gostam desse novo método (ROMA, 2002). }\end{array}$ \\
\hline $\begin{array}{l}\text { Professor e suas } \\
\text { relações com a } \\
\text { família dos alunos }\end{array}$ & $\begin{array}{l}\text { - Preocupação com a reação dos pais (BURAK, 1992; CALDEIRA, 1998; } \\
\text { BARBOSA, 2001). } \\
\text { Ausência de colaboração dos pais (ANASTÁCIO, 1990; BURAK, 1992; } \\
\text { MARTINELLO, 1994; BARBOSA, 2001; ROMA, 2002). }\end{array}$ \\
\hline
\end{tabular}

Quadro 2 - Obstáculos e resistências em aplicações com Modelagem Matemática

A seguir passaremos a analisar os dados apresentados no quadro anterior. 


\section{Análise}

Quanto à categoria professor e suas relações com o trabalho, percebemos, segundo Roma (2002), Jacobini (2004) e Dias (2005), que aplicações em Modelagem exigem dos professores melhor preparação das aulas, maior tempo nessa preparação e, também, um tempo diferenciado no momento da aula. O tempo que os professores têm que dedicar para essa forma de ensinar exige um replanejamento de todas as suas atividades, dentro e fora da escola.

Essa categoria extrapola a discussão de resistências e os obstáculos nas práticas com a Modelagem. Ela engloba, também, as condições do trabalho docente, que tem sido alvo de estudos de uma maneira geral. Autores mais ligados à pesquisa sobre formação de professores, em especial ao professor de Matemática, têm nos mostrado o quanto as condições das escolas dificultam e atrapalham suas formas de ensinar.

Freitas et al. (2005, p. 98) nos alertam para isso quando apontam que "o trabalho em mais de uma escola, em redes de ensino diferentes e, às vezes, em três períodos do dia, além de um número excessivo de alunos por sala de aula", são fatores preponderantes no desenvolvimento do trabalho dos professores. Os autores afirmam, ainda, que

[...] os dirigentes educacionais (diretores, coordenadores, secretários de ensino) impõem exigências ao trabalho docente, sobrecarregando os professores com atividades burocráticas e, muitas vezes, revelando insensibilidade para lidar com essa complexidade (FREITAS et al., 2005, p. 99).

Outra forma de ver essa problemática, além da carga real de trabalho, está relacionada também à questão de gênero. Para Tardif e Lessard (2005, p. 141):

[...] é importante ter presente a composição sexual do corpo docente, que é de $85 \%$ feminino no primário e $55 \%$ no secundário na maioria dos países [no Brasil parece que é maior ainda esse número]. Ora, com todos os dados atuais sobre essa questão, sabemos que as mulheres assumem também uma carga de trabalho na família claramente maior do que os homens. Nesse sentido, a semana média de 37 a 40 horas dos professores não é mais que a ponta do iceberg de seu trabalho pessoal, que é em parte um trabalho invisível aos olhos das autoridades escolares, sejam patronais ou sindicais. 
Mais especificamente, sobre a relação de trabalho do professor com a Modelagem, nossa pesquisa (ANASTÁCIO, 1990; BARBOSA, 2001; BURAK, 1987, 1992; CALDEIRA, 1998; DIAS, 2005; GAVANSKI, 1995; GAZZETA, 1987) aponta a insegurança dos professores diante do novo como uma das principais características. Aspecto de suma importância para as aplicações com a Modelagem, porque não se trata de buscar soluções, modificando a estrutura da escola e/ou sua forma de organização. Deparamos-nos, nesse sentido, com uma questão pessoal. A insegurança faz com que o professor resista no que diz respeito às mudanças. Decorrente disso, o professor sente, pela própria insegurança diante do novo, a falta de um profissional que tenha maior experiência e domínio sobre a Modelagem para acompanhá-lo durante as aulas. Isto fica evidente quando há relatos, nas teses e dissertações, de atividades de Modelagem em que havia o acompanhamento e auxílio do pesquisador na sala de aula. Nesses casos foi possível perceber uma tranquilidade do professor em trabalhar com as atividades. No entanto, percebemos que os professores, muitas vezes, desistiam das atividades quando esse pesquisador ia embora, alegando que não tinham mais interesse em continuar com o trabalho.

Muito recentemente, Oliveira e Barbosa (2011, p. 267) também identificaram que o trabalho com Modelagem nas escolas representa um grande desafio para os professores, levando-os, de certa maneira, a essa insegurança, tanto no que se refere às dinâmicas das aulas, muitas vezes diferente daquelas comumente encontradas, bem como a falta de previsibilidade do que ocorrerá nas aulas, conduzindo os professores a uma "zona de risco".

Isso acarreta uma resistência às mudanças, que, de certa forma, não acontece somente com a Modelagem, mas, também, por exemplo, ao uso das tecnologias de informação e comunicação. Segundo Robbins (1999, p. 399, apud SILVA, 2008, p. 41), "a resistência a mudanças é uma reação natural de indivíduos e de grupos ao inusitado, principalmente quando se encontram diante de transformações estruturais e funcionais no ambiente de trabalho" e aponta que as principais razões pelas quais os indivíduos, no nosso caso, os professores, podem resistir às mudanças, seriam hábitos, segurança, fatores econômicos, medo do desconhecido e processamento seletivo de informação.

Outra característica comum às condições de trabalho do professor, que não dificulta somente os trabalhos com Modelagem, é a grande quantidade de alunos por turma. Nossas escolas, principalmente as públicas, situadas nos grandes centros, encontram-se, muitas vezes, superlotadas. 
Quanto à categoria sobre a relação do professor com a escola, uma das dificuldades apresentadas pelos professores para o desenvolvimento das atividades de Modelagem é a ausência de colaboração da parte administrativa da própria escola. Isto está diretamente relacionado, em algumas instituições, com os objetivos educacionais que a Modelagem proporciona, muitas vezes, não alinhados aos objetivos dessas escolas. No caso das escolas públicas, há, atualmente, uma grande preocupação por parte dessas instituições com o desempenho dos seus alunos em exames institucionais externos, que acabam por ranqueá-las.

Na análise dos dados, também percebemos que há uma parcela de escolas em que não apenas a estrutura administrativa dificulta as aplicações com Modelagem, mas, também, a estrutura física impossibilita sobremaneira a formação de grupos de discussões para as realizações dessa atividade.

Alguns dados apresentados neste trabalho são corroborados por Biembengut (2009), quando discorre sobre a estrutura educacional com currículos de diferentes disciplinas, bem como sua carga horária estabelecida e períodos para cumprir cada ciclo da escola, afirmando que essas são algumas características dificultadoras de trabalhos com Modelagem.

Barbosa (1999, p. 78) também argumenta sobre o envolvimento da estrutura escolar como um impedimento para o sucesso da Modelagem nas escolas. Segundo este autor, "O contexto escolar, na visão de entrevistados, pode inibir iniciativas dos professores". Tais entrevistados falaram em "currículo atual", "conteúdos", "realidade da escola pública", "vestibular" e "tempo" como barreiras que a institucionalidade oferece à implementação da proposta de Modelagem" (BARBOSA, 1999, p. 78).

Modificar as formas de condução do trabalho docente pode, de fato, esbarrar em entraves apresentados pela escola. Silva (2008), por exemplo, afirma que a escola sempre foi um ambiente conservador. Seu posicionamento remete à manutenção de propostas educacionais baseadas nas tradições.

$\mathrm{Na}$ categoria em que estudamos as relações do professor com o currículo parece estar o ponto de maior entrave. Além dos professores acharem que fica muito difícil cumprir o programa quando se trabalha com Modelagem, há, também, uma preocupação com a sequência lógica dos conteúdos segundo organizados, principalmente nos livros didáticos. Aliado a isso, os professores ainda apontam como uma das dificuldades a questão do tempo. Muitos professores acreditam que com a Modelagem se gasta muito tempo, tanto na sua preparação, quanto na preparação da aula e, ainda, na sua realização em 
sala. Esse suposto excesso de tempo dificulta o cumprimento de todo o programa, provocando um mal-estar nos professores, tanto em relação à sua realização pessoal de, pelo menos cumprir o programa, quanto em relação à pressão que sofrem dos pais e dos administradores das escolas. Ainda notamos, segundo os trabalhos analisados, que há certa desconfiança, por parte dos professores, de que, efetivamente, as aplicações com Modelagem gerem construção do conhecimento.

Um dos pioneiros na Modelagem, Bassanezi (2002, p. 37), nos alerta sobre alguns obstáculos quanto à utilização dessa metodologia. Segundo ele, "estes obstáculos podem se caracterizar em três tipos: instrucionais, para os estudantes e para os professores". O autor explicita as razões dessas dificuldades, argumentando, no caso dos obstáculos instrucionais, sobre o tempo para execução do programa estabelecido, reafirmando se tratar de um tempo muito extenso. Encontramos, em nossa pesquisa, pontos de vista semelhantes: Barbosa (2001); Dias (2005); Fidelis (2005) e Roma (2002), cujos trabalhos evidenciam a mesma argumentação colocada por Bassanezzi (2002) de forma muito explícita.

Bassanezzi (2002) ainda relata que há uma dificuldade dos professores por falta de conhecimento do processo de Modelagem e, também, o medo de se encontrarem em situações constrangedoras, não sabendo a Matemática a ser utilizada em alguns casos de aplicação.

Frison et al.(2007, p. 347), relatam que professores têm "certa dificuldade para mudar a sequência e a forma de desenvolvimento dos conteúdos já instituídos nos planos de ensino da escola". Considerando que o texto não se refere a um estudo exclusivamente com professores de Matemática, é possível inferir que tal problema não é exclusivo dessa área do conhecimento. Essa situação é corroborada por Martinello (1994), que afirma que uma das preocupações de professores em adotar a Modelagem em suas salas de aula foi, justamente, a possibilidade de modificar a sequência dos conteúdos, deixando-a diferente da sequência lógica, evidenciando, assim, o receio de fugir das sequências dos programas preestabelecidos.

A partir dos dados coletados em Anastácio (1990); Burak (1987; 1992); Dias (2005); Fidelis (2005); Luz (2003) e Martinello (1994) evidenciou que a preocupação em cumprir o conteúdo tem se apresentado como uma grande dificuldade encontrada pelos professores ao aplicarem a Modelagem nas suas práticas. Barbosa (1999) também constata que os professores valorizam muito o cumprimento do programa, em virtude de seguirem um determinado cronograma 
adotado pelos livros didáticos, inclusive por estarem submetidos a alguma pressão por parte dos administradores das escolas, tais como supervisores e diretores ou pais. No caso das escolas particulares, a preocupação com o sucesso dos alunos no vestibular, que é ainda maior do que nas escolas públicas, aumenta a pressão.

A preocupação dos professores em cumprir o programa é observada por autores de diversas áreas. Segundo Boff, Frison e Del Pino (2007).

[...] no cotidiano da escola observa-se que uma das maiores preocupações do professor é 'cumprir o programa'. Este se impõe como verdadeiro dogma que precisa ser cumprido; raríssimas vezes o professor se questiona sobre a validade daquilo que está ensinando. (p. 83).

Quanto aos alunos e suas relações com a Modelagem, os trabalhos mostraram que boa parte dos alunos se identifica com a proposta, mas que nem todos gostam dela. Identificamos nas falas de alunos, nas pesquisas em teses e dissertações, que aqueles que reclamam da Modelagem se justificam pela necessidade de trabalhos extraclasse, tais como realizar pesquisa sobre um determinado tema ou mesmo se deslocar da cômoda posição de simplesmente ouvir.

Esse fenômeno tem uma peculiaridade interessante, que vai crescendo dos primeiros para os últimos anos. Crianças se identificam mais com a Modelagem, e adolescentes, mais do que os jovens; ou seja, à medida que se acumulam anos de escola, diminui a iniciativa da participação dos alunos em aplicação de Modelagem.

Bassanezzi (2002, p. 37), em relação a essa questão, afirma que o "uso da Modelagem foge da rotina do ensino tradicional e os estudantes, não acostumados ao processo, podem se perder e se tornar apáticos nas aulas”. Barbosa (2001) apresenta o relato de uma professora, afirmando que os alunos iriam ter certa rejeição com a proposta da Modelagem, e isso aconteceria devido às suas experiências anteriores. Roma (2002) apresenta resultados sobre alguma rejeição por parte dos alunos. Um dos aspectos se refere ao ensino noturno. Apesar de poucas referências sobre Modelagem, neste período de aula, Roma (2002) argumenta que os alunos sentem muita indisposição e cansaço em desenvolver as atividades de Modelagem.

Silveira e Jesus (2005) apresentam um estudo no qual relatam um trabalho de Modelagem desenvolvido em uma turma de $8^{a}$ série com quarenta alunos. Eles concluíram que, embora a situação estudada fosse de interesse dos alunos, 
pois os mesmos haviam escolhido a temática, pouco mais da metade participaram ativamente das atividades. Os autores afirmam que, embora os alunos tenham considerado interessante e significativo um trabalho daquela natureza, a Modelagem não resolveu totalmente o problema do interesse deles pelas aulas de Matemática.

Barbosa (1999, p. 80) ainda mostra que "os alunos não reagem positivamente às estratégias que os coloca no centro da ação pedagógica". Roma (2002) constata que os alunos não gostam desse novo método. Bassanezzi (2002) argumenta que as rejeições dos alunos quanto à Modelagem podem ser de duas naturezas: a formação heterogênea de uma classe pode ser um obstáculo para que alguns relacionem os conhecimentos teóricos adquiridos com as situações práticas em estudo, bem como o tema pode não ser do interesse de todos.

Franchi (1993, p. 102), ao relatar uma das suas experiências, fala das dificuldades dos alunos na fase inicial do trabalho com modelos.

Eles estão acostumados a ver o professor como transmissor de conhecimentos e, portanto, têm uma postura passiva em relação à aula. Esperam receber explicações e participar apenas fazendo perguntas ou resolvendo exercícios. Quando o trabalho coloca o centro do processo ensinoaprendizagem nos alunos, e quando os resultados dependem da ação deles, a aula passa a caminhar em ritmo lento, pois eles não estão acostumados a agir e nem sempre sabem o que fazer, ou por onde começar.

Finalmente, nos trabalhos que discutem sobre o professor e suas relações com as famílias dos alunos, identificamos preocupações por parte dos pais com relação à Modelagem. Uma justificativa, talvez a principal, é que para os pais a Matemática dita universal permite controlar os estudos dos seus filhos por meio dos cadernos e das tarefas. Quando se desenvolve atividades de Modelagem as tarefas costumam ser diferentes.

Conforme apresentado em Barbosa (2001); Burak (1992); Caldeira (1998); Anastácio (1990); Roma (2002) e Martinello (1994), além da preocupação dos pais com a ausência das tarefas, comumente encontrada nos cadernos dos alunos, pode-se citar, também, o sentimento de que os alunos não estão aprendendo, a ausência das intermináveis listas de exercícios de reforço e o pouco uso do livro didático. No caso do ensino médio, como já citado anteriormente, percebemos, a preocupação com os exames dos vestibulares. 
Outra dificuldade identificada diz respeito à ausência de colaboração dos pais nos trabalhos de pesquisas que a Modelagem exige, quando há elaboração e discussão dos temas escolhidos pelos alunos. É também perceptível o pouco envolvimento dos pais na locomoção dos filhos para trabalhos de campo, considerando deslocamentos dentro ou fora do bairro ou da comunidade em que esses alunos estudam ou moram.

Paula (2008, p. 10), ao tratar da importância da participação dos pais na educação dos filhos, afirma que essa participação

não deve ser a de assumir o papel de professor do filho em casa. Os pais, ou os responsáveis pela criança, podem colaborar valorizando as atividades didáticas desenvolvidas no ambiente escolar, incentivando a participação dos filhos nessas atividades, acompanhando o progresso deles, motivando os estudantes a superar dificuldades.

No caso da Modelagem, isso não é tão simples. Os pais também se sentem inseguros com essa nova forma de ensino adotado pela escola e ficam, de certa maneira, sem saber como podem colaborar no trabalho extraclasse dos alunos. Em um das atividades, porém, relatou-se a preocupação do pesquisador que os pais ou familiares dos alunos colaborassem com as atividades de Modelagem. Caldeira (1998) relata a participação do pai de um aluno que auxiliou nas atividades de Modelagem proferindo uma palestra sobre a construção de uma quadra poliesportiva. No entanto, percebemos, nas nossas buscas para as análises sobre esta categoria, poucos trabalhos que retratassem a participação dos pais em atividades com Modelagem nas salas de aula.

\section{Conclusões}

O objetivo desta pesquisa foi descrever e analisar os obstáculos e resistências de professores e futuros professores, egressos de cursos de formação, em desenvolver atividades relacionadas à Modelagem nas suas práticas docentes, conforme relatados em dissertações e teses.

Para tal, voltamos o nosso olhar a outras pesquisas em busca de aspectos que se aproximavam dos obstáculos e resistências encontradas nas teses e dissertações, quanto à aplicabilidade da Modelagem, e localizamos alguns autores que discutiram o assunto, alguns deles já apresentados anteriormente neste texto.

Esses autores, de uma forma geral, corroboram os dados apresentados 
no Quadro 2. O que, de certa maneira, nos permite ressaltar indicações de novas pesquisas na área, sobre o que e como fazer para contornar esses obstáculos e resistências aqui apontados, para que, efetivamente, a Modelagem passe a fazer parte do cotidiano escolar.

De uma maneira geral, Lozada (2009, p. 12-13) nos apresenta algumas dessas resistências envolvendo Modelagem em sala de aula, como por exemplo: [...] falta de conhecimento sobre o processo de MM [Modelagem Matemática], dificuldades dos docentes em relação à alguns conteúdos matemáticos, as dificuldades dos alunos em relação à alguns conteúdos matemáticos, a falta de interesse dos alunos e o cumprimento do conteúdo programático, constituíram-se como motivos que impedem a utilização da MM em sala.

Biembengut (2009) também nos apresenta duas razões no que se refere às dificuldades de implementação da Modelagem em sala de aula: a formação de professores e os exames de avaliação dos estudantes. A dificuldade dos professores, segundo a autora, está no fato de, nos cursos de graduação, as disciplinas serem divididas de forma estanque, muito vinculadas e, ainda, no método de transmissão de conteúdos sem significado na vida prática dos alunos. No caso das avaliações, a dinâmica das provas de vestibular e concursos sem nenhum vínculo com projetos e sustentadas nos moldes tradicionais.

Tais indicações se aproximam das nossas análises e também nos credenciam a afirmar que existe, na educação matemática brasileira, muita resistência por parte dos professores em assumir, de forma mais consistente, a Modelagem como uma prática de sala de aula.

Souza e Espírito Santo (2007, p. 786) também nos alertam sobre as dificuldades dos professores nos apontando fatores de impedimento e de limitação à sua disposição em utilizar a Modelagem em sua sala de aula.

Predominantemente, as barreiras descritas pelos professores e também por alguns pesquisadores tiveram como organização escolar de utilização da Modelagem, à organização em séries anuais, ou simplesmente organizações escolares com medidas semelhantes à ela, ou seja, cursos com tais ações: obrigatoriedade de cumprimento integral de conteúdos disciplinares pré-estabelecidos; período anual ou semestral de escolarização; conteúdos disciplinares dispostos de forma linear e etc. 
As análises dos dados e a comparação de tais dados com outras pesquisas no campo nos mostraram que os obstáculos e as resistências, quando se trata de aplicações de Modelagem nas salas de aula, apontam dificuldades na sua implementação em quase todos os âmbitos constituintes do trabalho docente: preparação das aulas; relação com os alunos; relação com a família dos alunos; estrutura administrativa e pedagógica das escolas; currículo e questões pessoais, como por exemplo, a insegurança diante do novo.

Com tudo isso, acreditamos que os estudos e as pesquisas envolvendo a Modelagem enquanto prática pedagógica apontam para um novo rumo de indagações, não mais sobre o que é a Modelagem, mas como é possível a sua incorporação e manutenção nos sistemas escolares.

\section{Referências}

ANASTÁCIO, M. Q. A. Considerações sobre a Modelagem Matemática e a Educação Matemática. 1990. 100 f. Dissertação (Mestrado em Educação Matemática) - Instituto de Geociências e Ciências Exatas, Universidade Estadual Paulista, Rio Claro, 1990.

BARBOSA, J. C. O que pensam os professores sobre a Modelagem Matemática? Zetetiké, Campinas, v. 7, n. 11, p. 67- 85, jul./dez. 1999.

BARBOSA, J. C. Modelagem Matemática: concepções e experiências de futuros professores. 2001. 253 f. Tese (Doutorado em Educação Matemática) - Instituto de Geociências e Ciências Exatas, Universidade Estadual Paulista, Rio Claro, 2001.

BARBOSA, J. C. Sobre a pesquisa em Modelagem Matemática no Brasil. In: CONFERÊNCIA NACIONAL SOBRE MODELAGEMNA EDUCAÇÃO MATEMÁTICA, 5., 2007, Ouro Preto. Anais... Ouro Preto: UFOP/UFMG, 2007. 1 CDROM.

BASSANEZI, R. C. Ensino-aprendizagem com Modelagem Matemática. São Paulo: Contexto, 2002.

BIEMBENGUT, M. S. Modelagem Matemática \& Implicações no Ensino Aprendizagem de Matemática. Blumenau: Editora da FURB, 1999.

BIEMBENGUT, M. S. 30 Anos de Modelagem Matemática na educação brasileira: das propostas primeiras às propostas atuais. Alexandria Revista de Educação em Ciência e Tecnologia, Florianópolis, v. 2, n. 2, p. 7-32, jul. 2009. Disponível em: $<$ http://alexandria.ppgect.ufsc.br/files/2012/03/mariasalett.pdf>. Acesso em: 11 out. 2011. 
BIEMBENGUT, M. S.; HEIN, N.; DOROW, K. C. Mapeamento das pesquisas sobre Modelagem Matemática no ensino brasileiro: análise das dissertações e teses desenvolvidas no Brasil. In: CONFERÊNCIA NACIONAL SOBRE MODELAGEM NA EDUCAÇÃO MATEMÁTICA, 5., 2007, Ouro Preto. Anais... Ouro Preto: UFOP/UFMG, 2007. 1 CD-ROM.

BIEMBENGUT, M. S.; SCHMITT, A. L. F.; VIEIRA, E. M. Um panorama das produções brasileiras de Modelagem Matemática no ensino. In: ENCONTRO PARANAENSE DE MODELAGEM EM EDUCAÇÃO MATEMÁTICA, 3. 2009, Belém. Anais... Belém: UFPA, 2009. 1 CD-ROM.

BOFF E. T. de O.; FRISON M. D; DEL PINO J. C. Formação inicial e continuada de professores: o início de um processo de mudança no espaço escolar. In: GALIAZZI, M. do C. et al. (Org.). Construção curricular em rede na educação em ciências: uma aposta de pesquisa na sala de aula. Ijuí: Editora Unijuí, 2007. p. 69-90.

BURAK, D. Modelagem Matemática: uma metodologia alternativa para o ensino da Matemática na 5ª serie. 1987. 186 f. Dissertação (Mestrado em Educação Matemática) - Instituto de Geociências e Ciências Exatas, Universidade Estadual Paulista, Rio Claro, 1987.

BURAK, D. Modelagem Matemática: ações e interações no processo de ensino aprendizagem. 1992. 459f. Tese (Doutorado em Educação) - Faculdade de Educação, Universidade Estadual de Campinas, Campinas, 1992.

CALDEIRA, A.D. Educação Matemática eAmbiente: um contexto de mudança. 1998. 158f. Tese (Doutorado em Educação) - Faculdade de Educação, Universidade Estadual de Campinas, Campinas, 1998.

CALDEIRA, A.D. Modelagem Matemática: um outro olhar. Alexandria. Revista de Educação em Ciência e Tecnologia, Florianópolis, v. 2, n. 2, p. 33-54, jul. 2009. Disponível em: <http://alexandria.ppgect.ufsc.br/files/2012/03/ademir.pdf>. Acesso em: 07 mai. 2011.

D’AMBROSIO, U. Educação para uma Sociedade em Transição. Campinas: Papirus Editora, 1999.

D’AMBROSIO, U. Etnomatemática - elo entre as tradições e a modernidade. Belo Horizonte: Autêntica, 2001.

DIAS, M. R. Uma experiência com Modelagem Matemática na formação continuada de professores. 2005. 199f. Dissertação (Mestrado em Ensino de Ciências e Educação Matemática) - Universidade Estadual de Londrina, Londrina, 2005. 
FIDELIS, R. Contribuições da Modelagem Matemática para o pensamento reflexivo: um estudo. 2005. 178f. Dissertação (Mestrado em Ensino de Ciências e Educação Matemática) - Universidade Estadual de Londrina, Londrina, 2005.

FIORENTINI, D. Estudo de algumas tentativas pioneiras de pesquisa sobre o uso da Modelagem Matemática no ensino. In: INTERNATIONAL CONGRESS ON MATHEMATICAL EDUCATION ICME, $8^{\text {th }}$., 1996, Sevilha. Anais... Sevilha: ICME, 1996. p. 235-248.

FRANCHI, R. H. de O. L. A Modelagem Matemática como estratégia de aprendizagem do calculo diferencial e integral nos cursos de engenharia. 1993. 148f. Dissertação (Mestrado em Educação Matemática) - Instituto de Geociências e Ciências Exatas, Universidade Estadual Paulista, Rio Claro, 1993.

FREITAS, M. T. M. et al. O desafio de ser professor de Matemática hoje no Brasil. In: FIORENTINI, D.; NARACATO, A. M. (Org. ). Cultura, formação e desenvolvimento profissional de professores que ensinam Matemática. Campinas: Editora Gráfica FE/ UNICAMP, 2005. p. 89-105.

FRISON, M. et al. Situação de estudo: conhecendo o câncer - um caminho para a vida. In: GALIAZZI, M. do C; AUTH, M.; MORAES, R.; MANCUSO, R. (Orgs.).

Construção curricular em rede na educação em ciências: uma aposta de pesquisa na sala de aula. Ijuí: Editora Unijuí, 2007. p. 337-355.

GAVANSKI, D. Uma experiência de estágio supervisionado norteado pala Modelagem Matemática: indícios para uma ação inovadora. 1995. 174f. Dissertação (Mestrado em Educação) - Universidade Estadual do Centro-Oeste do Paraná, Guarapuava, 1995.

GAZZETTA, M. A Modelagem como estratégia de aprendizagem da Matemática em cursos de aperfeiçoamento de professores. 1989. 150f. Dissertação (Mestrado em Educação Matemática) - Instituto de Geociências e Ciências Exatas, Universidade Estadual Paulista, Rio Claro, 1989.

GOTTSCHALK, C. M. C. A construção e a transmissão do conhecimento matemático sob uma perspectiva wittgensteiniana. Caderno Cedes, Campinas, v. 28, n. 74, p. 7596, jan./abr. 2008. Disponível em:

$<$ http://www.scielo.br/

scielo.php?script=sci_arttext\&pid=S010132622008000100006\&lng=en\&nrm=iso $>$. Acesso em: 23 fev. 2010.

GOTTSCHALK, C. M. C. A natureza do conhecimento matemático sob a perspectiva de Wittgenstein: algumas implicações educacionais. Caderno de História e Filosofia da Ciência, Campinas, série 3, v. 14, n. 2, p. 305-334, 2004. Disponível em: < http://www.cle.unicamp.br/cadernos/pdf/Cristiane\%20Gottschalk.pdf>. Acesso em: 14 mar. 2010. 
JACOBINI, O. A Modelagem Matemática como instrumento de ação política na sala de aula. 2004. 225f. Tese (Doutorado em Educação Matemática) - Instituto de Geociências e Ciências Exatas, Universidade Estadual Paulista, Rio Claro, 2004.

LOZADA, C. O. A prática da Modelagem Matemática e a formação de professores: as percepções iniciais dos professores em um curso de especialização em Modelagem Matemática. In: CONFERÊNCIA NACIONAL SOBRE MODELAGEMNA EDUCAÇÃO MATEMÁTICA, 6., 2009, Londrina. Anais... Londrina: UEL, 2009. 1 CDROM.

LUZ, E. F. Educação a Distância e Educação Matemática: contribuições mútuas no contexto teórico-metodológico. 2003. 180f. Tese (Doutorado em Engenharia de Produção e Sistemas) - Departamento de Engenharia de Produção e Sistemas, Universidade Federal de Santa Catarina, Florianópolis, 2003.

MARTINELLO, D. Modelação Matemática, uma alternativa para o ensino da Matemática no primeiro grau. 1994. 162 f. Dissertação (Mestrado em Educação) Universidade Regional de Blumenau, Blumenau, 1994.

OLIVEIRA, A. M. P.; BARBOSA, J. C. Modelagem Matemática e situações de tensão e as tensões na prática de Modelagem. Bolema, Rio Claro, v. 24, n. 38, p. 265-296, abr. 2011.

PAULA. K. C. M. A família, o desenvolvimento das atitudes em relação à Matemática e a crença de auto-eficácia. 2008. 186f. Dissertação (Mestrado em Educação) Faculdade de Educação, Universidade Estadual de Campinas, Campinas, 2008.

ROMA, J. E. O curso de especialização em Educação Matemática da PUC-Campinas: reflexos na prática pedagógica dos egressos. 2002. 208f. Dissertação (Mestrado em Educação) - Pontifícia Universidade Católica de Campinas, Campinas. 2002.

SILVA, C. A. M. Tecnologias da informação e comunicação na prática pedagógica de professores da área tecnológica de escolas técnicas: aprovação, resistência e indiferença. 2008. 141f. Dissertação (Mestrado em Educação) - Universidade Estácio de Sá, Curitiba, 2008.

SILVEIRA, E. Modelagem Matemática em educação no Brasil: entendendo o universo de teses e dissertações. 2007. 197f. Dissertação (Mestrado em Educação) - Setor de Educação, UFPR, Curitiba, 2007.

SILVEIRA, E.; JESUS, R. V. de. Projetando uma sala de informática na escola com o uso da Modelagem Matemática. In: CONFERÊNCIA NACIONAL SOBRE MODELAGEM E EDUCAÇÃO MATEMÁTICA, 4., 2005, Feira de Santana. Anais... Feira de Santana: Universidade Estadual de Feira de Santana, 2005. 1 CD-ROM. 
SOUZA, E. G.; ESPÍRITO SANTO, A. O. A organização escolar em ciclos: um caminho para incluir a Modelagem Matemática na prática escolar docente. In: CONFERÊNCIA NACIONAL SOBRE MODELAGEM NA EDUCAÇÃO MATEMÁTICA, 5., 2007, Ouro Preto. Anais... Ouro Preto: UFOP/UFMG, 2007. 1 CD-ROM.

STAHL, N. P. O ambiente e a Modelagem Matemática no ensino de cálculo numérico. 2003. 145f. Tese (Doutorado em Educação Matemática) - Faculdade de Educação, Universidade Estadual de Campinas, Campinas, 2003.

TARDIF, M.; LESSARD, C. O trabalho docente: elementos para uma teoria da docência como profissão de interações humanas. Rio de Janeiro: Vozes, 2005.

WITTGENSTEIN, L. Investigações filosóficas. Tradução de: José Carlos Bruni. São Paulo: Editora Nova Cultural Ltda, 1999.

Submetido em Setembro de 2010. Aprovado em Fevereiro de 2012. 


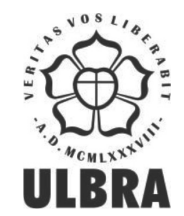

\section{ACTA SCIENTIAE}

Revista de Ensino de Ciências e Matemática

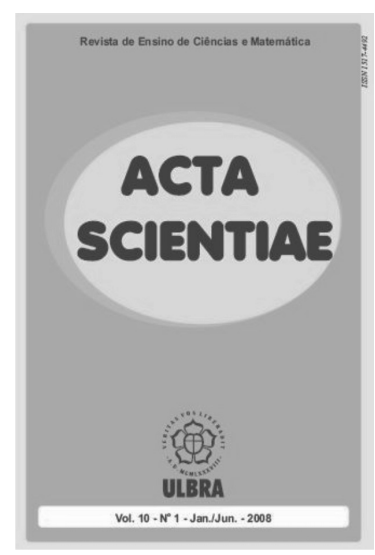

A Revista Acta Scientiae teve sua origem em 1999, mediante publicação de artigos oriundos dos pesquisadores das áreas de Ciências Naturais e Exatas da Universidade Luterana do Brasil - ULBRA Canoas (RS). Com sua indexação junto ao IBICT - Instituto Brasileiro de Informação em Ciência e Tecnologia (ISSN no. 1517-4492), é reconhecida como um espaço de publicação tanto de Ciências e Matemática como de Ensino dessas áreas. Entretanto, a partir do Volume 7, Número 1, 2005, Jan-Jun, a revista passa a publicar artigos exclusivos da área de Ensino de Ciências e Matemática, sendo editada desde sua fundação em dois números anuais. Assim, constitui-se em mais uma opção para publicação de artigos científicos dessa região de inquérito.

Confira: http://www.ulbra.br/actascientiae

Você poderá realizar download dos exemplares da revista, encontrará informações para submissão e avaliação dos artigos.

\section{Atenção!}

A Revista Acta Scientiae é de fluxo contínuo para o recebimento de artigos. Além disso, ela é uma revista de divulgação impressa e online.

\section{Informações:}

mauriciomatematica@gmail.com

actascientiae@ulbra.br 